\title{
EDUCAÇÃO ESPECIAL, NECESSIDADES ESPECIAS E FORMAÇÃO DE DOCENTES.
}

\author{
SPECIAL EDUCATION, SPICE NEEDS AND TEACHER TRAINING
}

\author{
Poliana Mansor Almança ${ }^{1}$ \\ Rosane Aparecida dos Santos Rocha²
}

\section{RESUMO}

Este presente tem como objetivo enfatizar a necessidade de se pensar a verdadeira revolução que começa a ocorrer em todo o contexto educacional, pois a inclusão dos alunos com necessidades especiais passa a ser tarefa essencial na nova empreitada educacional. Nesse âmbito, temos que contar com o contexto cultural, financeiro ou físico para atender a todos os alunos que possuem algum tipo de dificuldade de aprendizado. Assim, mostramos que a escola tem papel fundamental para a aprendizagem e facilitação da inclusão, quer fornecendo material didático adaptados quer oferecendo cursos aos educadores com a finalidade de conhecer novas práticas de ensino e adaptação no currículo escolar, por exemplo.

Palavras chaves: Educação Especial. Necessidades Especiais. Formação de Professores. Participação.

\section{ABSTRACT}

This paper aims to emphasize the need to think about the real revolution that begins to occur throughout the educational context, because the inclusion of students with special needs becomes essential task in the new educational undertaking. In this context, we have to rely on the cultural, financial or physical to cater to all students who have some type of learning disability. Thus, we show that the school has key role in learning and facilitating inclusion, either by providing teaching materials or offering tailored courses to educators in order to meet new teaching practices and adapting the school curriculum, for example.

Keywords: Special Education. Special Needs. Training.Teachers. Participation.

\footnotetext{
${ }^{1}$ Mestranda em Ciências da Educação pela FICS-Facultad Interamericana de Ciências Sociales Licenciada em Ciências Biológicas. Especialista em Análise Clínicas e Patológicas. Especialista em Educação ambiental. Licenciada em Filosofia. Especialista em Educação Especial e Inclusiva. E-mail: polianaalmanca@hotmail.com.

${ }^{2}$ Mestranda em Ciências da Educação pela FICS-Facultad Interamericana de Ciências Sociales- Especialista em Educação Especial pela faculdade São Francisco- Graduada em Pedagogia pela Fundação Universidade Do Tocantins, E-mail: rosane_santos2@hotmail.com.
} 


\section{INTRODUÇÃO}

No momento em que nós enquanto cidadãos entendermos que somente através da educação as possibilidades de inclusão das pessoas com necessidades especiais podem se concretizar, a sociedade abrirá de forma natural os espaços a quem tem alguma limitação física ou psicológica, modificando suas estruturas e serviços oferecidos, tornando-se a cada dia um lugar onde as pessoas de todos os tipos e inteligências possam sentir-se a vontade para desenvolver suas habilidades e aptidões de acordo com suas possibilidades, sendo reconhecidas pelas suas potencialidades e não discriminadas e excluídas por suas limitações.(Artigo, Tópicos Especiais em Educação de Catiuscia Nagel, publi.20015). Ainda no que se refere o artigo, sabemos que a inclusão de um indivíduo na sociedade depende do patrimônio cultural que ele recebe, isto faz da educação um pilar fundamental para o desenvolvimento deste, pois é objetivo da educação adaptar e ajudar no desenvolvimento das potencialidades, contribuindo na construção da personalidade e caráter de cada ser humano.

A educação inclusiva segundo (BEYER,2006), é uma ação humana e democrática, é um processo que amplia a participação dos estudantes nas escolas, auxiliando no desenvolvimento das pessoas. Ensina a compreender que as diferenças estão em todos os lugares. Ao mesmo tempo transforma a realidade escolar das pessoas com necessidades especiais dando o direito a todos a educação. Infelizmente muitos alunos estão tendo estes direitos negado por apresentarem condições diferenciadas.

No que se refere o autor a grande dificuldade que encontramos nas escolas especiais deve ser a limitação no horizonte social das crianças com necessidades especiais. Enquanto estas precisam da convivência com a criança condições cognitivas e sócio afetiva diferenciado das suas, veem através das situações pedagógicas e sociais correspondente, atreladas a um modelo limitado de interação. (BEYER,2006). Consoante a estas questões objetivamos identificar pontos fortes e fracos no curso de formação de professores do Centro Educacional Candido Rondon no que se refere ao atendimento de pessoas com necessidades especiais e desta forma possibilitar reflexões

\footnotetext{
${ }^{1}$ Mestranda em Ciências da Educação pela FICS-Facultad Interamericana de Ciências Sociales Licenciada em Ciências Biológicas. Especialista em Análise Clínicas e Patológicas. Especialista em Educação ambiental. Licenciada em Filosofia. Especialista em Educação Especial e Inclusiva. E-mail: polianaalmanca@hotmail.com.

${ }^{2}$ Mestranda em Ciências da Educação pela FICS-Facultad Interamericana de Ciências Sociales- Especialista em Educação Especial pela faculdade São Francisco- Graduada em Pedagogia pela Fundação Universidade Do Tocantins, E-mail: rosane_santos2@hotmail.com.
} 
quanto à qualidade que vem tratar da capacitação acadêmica destes graduandos quanto à educação inclusiva.

\section{METODOLOGIA}

A metodologia utilizada para esta pesquisa foi de cunho bibliográfico onde foram pesquisados em sites de publicação acadêmica como: Scielo livros entre os anos de 1991 e 2008 e utilizaram-se como descritores as seguintes palavras necessidades especiais, educação inclusiva, educação especial e o estudo referente à educação inclusiva, com base em dados extraídos de pesquisa de campo com alunos matriculados no curso de pedagogia do $4^{\circ}$ e $6^{\circ}$ semestre.

Na primeira seção, busca-se uma abordagem teórica sobre a inclusão educacional, o papel do professor e da escola para atender as diversidades de inteligências da qual se depara nas salas de aulas e qual a melhor maneira de lidar com estas diferenças existentes. Na segunda seção, procura-se elucidar alguns conceitos do que são necessidades educacionais, os diversos tipos de dificuldades de aprendizagem, caracterização e os recursos educacionais dispostos e adaptáveis aos alunos, além de como o uso das tecnologias assistivas podem ajudar os docentes no processo inclusivo.

E por fim na terceira e última seção deste trabalho monográfico, estão às considerações e análises a respeito do estudo de caso, onde o questionário foi baseado a partir da leitura das referências bibliográficas no que diz respeito ao tema educação inclusiva e as melhores técnicas sugeridas pelos autores pesquisados.

\section{INCLUSÃO: HISTÓRICO E CONCEITO}

Falar de histórico da inclusão nos remete a falar, também, da trajetória histórica dos portadores de deficiência desde os primórdios de sua existência. As mudanças de atitudes em relação aos deficientes no decorrer da história podem ser relacionadas ao que Makhoul (2007) chama de "atendimento as necessidades básicas do homem". Esse atendimento foi registrado, pelo autor, como primeiro ato histórico de busca pela

\footnotetext{
${ }^{1}$ Mestranda em Ciências da Educação pela FICS-Facultad Interamericana de Ciências Sociales Licenciada em Ciências Biológicas. Especialista em Análise Clínicas e Patológicas. Especialista em Educação ambiental. Licenciada em Filosofia. Especialista em Educação Especial e Inclusiva. E-mail: polianaalmanca@hotmail.com.

${ }^{2}$ Mestranda em Ciências da Educação pela FICS-Facultad Interamericana de Ciências Sociales- Especialista em Educação Especial pela faculdade São Francisco- Graduada em Pedagogia pela Fundação Universidade Do Tocantins, E-mail: rosane_santos2@hotmail.com.
} 
sobrevivência do homem e entender a forma como os homens vem se sustentando isso nos será permitido compreender a diferença e a necessidade de atendimento especial para deficientes.

Para isso faz-se necessário retomar a história do significado da deficiência nos diferentes momentos históricos. Começando pela Antiguidade, onde os povos eram nômades e dependiam das trocas de habitat para se sustentarem. Nesse período os portadores de deficiência eram vistos como obstáculo para esses deslocamentos feitos pelos homens e então eram abandonados pelo restante da comunidade. Em alguns povos antigos o corpo deficiente era considerado inadequado, pois não estava apto para o trabalho. $O$ "extermínio acontecia sempre que a deficiência implicasse dependência econômica ou incapacidade para o trabalho, ou seja, sempre que essas pessoas não conseguissem atender às suas necessidades básicas" (Makhoul, 2007, p.87).

Segundo o autor (MARQUES apud POLIA, 2008, p. 31), Na Idade Média o corpo deficiente ganha direito à vida, mas é estigmatizado. A deficiência foi relacionada como sinônimo de pecado e isso justificava a segregação e até eliminação. Com a Modernidade, período em que surgem a produção voltada para o mercado e a modernização dos meios de produção, o corpo passou a ser considerado uma máquina e a deficiência passa a ser relacionada à disfuncionalidade, a partir daí foi-se marginalizando ainda mais os deficientes.

"O produto histórico dessa mudança no comportamento social e econômico do homem moderno foi a consolidação de uma formação discursiva fundada na dicotomia semântica e prática da eficiência versus deficiência. Além do aspecto biológico da anormalidade, a deficiência passou a ser entendida como um fator impeditivo para o trabalho fabril" (MARQUES apud POLIA, 2008, p. 31).

Com esse ideário de que os portadores de deficiência não seguem os avanços da sociedade e que a segregação poderia ser a sugestão mais apropriada para todos é que surgem as instituições, consideradas como locais onde as necessidades básicas do deficiente estariam garantidas. Podemos colocar dentro dessas instituições as escolas de educação especial, que eram "administradas por instituições voluntárias, em sua

\footnotetext{
${ }^{1}$ Mestranda em Ciências da Educação pela FICS-Facultad Interamericana de Ciências Sociales Licenciada em Ciências Biológicas. Especialista em Análise Clínicas e Patológicas. Especialista em Educação ambiental. Licenciada em Filosofia. Especialista em Educação Especial e Inclusiva. E-mail: polianaalmanca@hotmail.com.

${ }^{2}$ Mestranda em Ciências da Educação pela FICS-Facultad Interamericana de Ciências Sociales- Especialista em Educação Especial pela faculdade São Francisco- Graduada em Pedagogia pela Fundação Universidade Do Tocantins, E-mail: rosane_santos2@hotmail.com.
} 
maioria religiosa, com consentimento governamental, mas sem nenhum outro tipo de envolvimento por parte do governo. (...) Surgiram também escolas especiais, assim como centro de reabilitação e oficinas protegidas de trabalho, pois a sociedade começou a admitir que pessoas deficientes pudessem ser produtivas se recebessem escolarização e treinamento profissional." (SASSAKI, 2003, p. 112).

Ainda no que se refere o autor (SASSAKI, 2003, p. 112), preocupação com a educação dos portadores de deficiência se iniciou na década de 30 com o pensamento de acabar com as desigualdades, diminuindo as diferenças para uma educação mais qualificada. A partir desse marco inicial foi-se implementando vários métodos para mudar a forma de educação até que, nas décadas de 60/70, as modificações vão ganhando destaque, pois nessa época há a democratização da sociedade e da educação, e as pessoas portadoras de deficiência começam a lutar pela efetivação de seus direitos; isto faz com que surja um processo educativo acessível a todos. E assim que se deu início a luta pela educação dos portadores de deficiência que segue até a implantação da lei de inclusão para todos na educação, que começou a ser discutida em encontros propostos para todos os governos com a finalidade de se unir contra uma sociedade excludente.

\section{FASE DA INTEGRAÇÃO}

A fase da integração na educação de portadores de deficiência é marcada pelo surgimento de classes especiais dentro das escolas comuns. Isso aconteceu, como coloca Sassaki (2003), não por motivos humanitários, mas como garantia que essas crianças portadoras de deficiência não iriam atrapalhar o trabalho dos professores de instruir os demais alunos ditos normais e interferir no processo de aprendizagem dos demais colegas de sala.

A ideia de integrar deficientes em classes especiais surgiu para derrubar a prática de exclusão a que esses deficientes foram submetidos até então. O início dessa ideia deuse mais ou menos a partir do final da década de 60, quando o movimento começou a procurar inserir as pessoas portadoras de deficiência nos sistemas sociais gerais como a educação, o trabalho, a família e o lazer (SASSAKI, 2003, p. 31).

\footnotetext{
${ }^{1}$ Mestranda em Ciências da Educação pela FICS-Facultad Interamericana de Ciências Sociales Licenciada em Ciências Biológicas. Especialista em Análise Clínicas e Patológicas. Especialista em Educação ambiental. Licenciada em Filosofia. Especialista em Educação Especial e Inclusiva. E-mail: polianaalmanca@hotmail.com.

${ }^{2}$ Mestranda em Ciências da Educação pela FICS-Facultad Interamericana de Ciências Sociales- Especialista em Educação Especial pela faculdade São Francisco- Graduada em Pedagogia pela Fundação Universidade Do Tocantins, E-mail: rosane_santos2@hotmail.com.
} 
Essa nova abordagem teve alguns princípios propulsores, como por exemplo, o princípio da normalização, que "tinha como pressuposto básico a ideia de que toda pessoa portadora de deficiência, especialmente aquela portadora de deficiência mental, tem o direito de experienciar um estilo de padrão de vida que seria comum ou normal à sua própria cultura" (MENDES apud SASSAKI, 2003, p. 31). Na década de 70, a normalização passou a abranger serviços e ambientes, e condições de vida, passando a oferecer, aos portadores de necessidades especiais, modos e condições de vida o mais semelhante possível às do resto da sociedade.

Na perspectiva do autor (MENDES apud SASSAKI, 2003, p. 31) neste período de 1970 que houve, a partir da criação de Serviços de Educação Especial, a expansão de ofertas de vagas nas escolas aos alunos com necessidades educativas especiais em classes especiais, salas de recursos e unidades de ensino itinerante, cedidas pelas Secretarias de Educação. Porém esses serviços atenderam mais aos alunos com histórico de fracasso escolar do que os deficientes. Isso fez com que a Educação Especial passasse a ter um duplo papel: o de democratização do ensino ao mesmo tempo o de segregação no ensino.

Já na década de 80 se desenvolveu o princípio de mainstreaming, que significa levar os alunos o mais possível para os serviços educacionais disponíveis na corrente principal da comunidade (SASSAKI, 2003, p. 32). Esse princípio pode ocorrer nas classes regulares, em intervalos ou durante o almoço, em matérias específicas como música, artes, educação física; e em atividades extracurriculares.

A fase de integração social é caracterizada pelo esforço de inserir na sociedade pessoas com deficiência "que alcançaram um nível de competência compatível com os padrões sociais vigentes". Ela tem a capacidade de inserir o portador de deficiência na sociedade, mas desde que este esteja capacitado a superar "as barreiras físicas, programáticas e atitudinais nela existentes." (SASSAKI, 2003, p. 34).

No que se refere acima o autor (SASSAKI, 2003, p. 34), a integração não exige mudanças da sociedade. Nesse modelo a sociedade permanece praticamente de braços cruzados e recebe esses portadores de deficiência inseridos. Ela pressupõe que os

\footnotetext{
${ }^{1}$ Mestranda em Ciências da Educação pela FICS-Facultad Interamericana de Ciências Sociales Licenciada em Ciências Biológicas. Especialista em Análise Clínicas e Patológicas. Especialista em Educação ambiental. Licenciada em Filosofia. Especialista em Educação Especial e Inclusiva. E-mail: polianaalmanca@hotmail.com.

${ }^{2}$ Mestranda em Ciências da Educação pela FICS-Facultad Interamericana de Ciências Sociales- Especialista em Educação Especial pela faculdade São Francisco- Graduada em Pedagogia pela Fundação Universidade Do Tocantins, E-mail: rosane_santos2@hotmail.com.
} 
portadores de deficiência devem "mudar" e se adequar aos sistemas de ensino e à sociedade, o que implica em um esforço unilateral dessas pessoas excluídas para fazerem parte da sociedade.

"A integração tinha como pressuposto que o problema residia nas características das crianças excepcionais, na medida em que centrava toda a sua argumentação na perspectiva da detecção mais precisa dessas características e no estabelecimento de critérios baseados nessa detecção para incorporação ou não pelo ensino regular, expresso pela afirmação "sempre que suas condições pessoais permitirem". (Conferência Mundial de Educação Especial apud MOREJÓN, 2001, p. 39).

\section{FASE DA INCLUSÃO}

O movimento de inclusão das pessoas portadoras de deficiência começou no início dos anos 90 quando foi realizado uma Conferência em Jomtien, na Tailândia (1990) onde os países se comprometeram a organizar políticas educativas que proporcionasse o acesso à educação de todos, inclusive os portadores de deficiência. Mas as metas estabelecidas pela Conferência não foram atingidas.

Com o fracasso da primeira Conferência, foi realizada, no ano de 1994, a Conferência Mundial sobre Necessidades Especiais: acesso e qualidade, na cidade de Salamanca (Espanha), que foi considerada um marco histórico e muito significativo nessa jornada. A Declaração de Salamanca teve muita importância no fato de lembrar aos governos que as crianças deficientes devem ser incluídas, que elas devem ser vistas como parte de um amplo grupo de crianças e que seu direito à educação lhe estava sendo negado, e esclareceu questões sobre a inclusão escolar desses deficientes (MAKHOUL, 2007). Esse marco resultou no compromisso dos noventa e dois países e vinte e cinco organizações em prol da Educação para todos, onde todos reconheceram a necessidade e a urgência de garantir a educação para as crianças, jovem e adulta com necessidades educativas especiais no quadro do sistema regular de educação (DECLARAÇÃO DE SALAMANCA, 1994).

\footnotetext{
${ }^{1}$ Mestranda em Ciências da Educação pela FICS-Facultad Interamericana de Ciências Sociales Licenciada em Ciências Biológicas. Especialista em Análise Clínicas e Patológicas. Especialista em Educação ambiental. Licenciada em Filosofia. Especialista em Educação Especial e Inclusiva. E-mail: polianaalmanca@hotmail.com.

${ }^{2}$ Mestranda em Ciências da Educação pela FICS-Facultad Interamericana de Ciências Sociales- Especialista em Educação Especial pela faculdade São Francisco- Graduada em Pedagogia pela Fundação Universidade Do Tocantins, E-mail: rosane_santos2@hotmail.com.
} 
Em Salamanca (1994), ainda é pedido aos governos que participavam da elaboração do documento que:

- Conceder a maior prioridade, através das medidas de política e através das medidas orçamentais, ao desenvolvimento dos respectivos sistemas educativos, de modo a que possam incluir todas as crianças, independentemente das diferenças ou dificuldades individuais,

- Adotar como matéria de lei ou como política o princípio da educação inclusiva, admitindo todas as crianças nas escolas regulares, a não ser que haja razões que obriguem a proceder de outro modo;

- Desenvolver projetos demonstrativos e encorajar o intercâmbio com países que têm experiência de escolas inclusivas;

- Estabelecer mecanismos de planejamento, supervisão e avaliação educacional para crianças e adultos com necessidades educativas especiais, de modo descentralizado e participativo;

- Encorajar e facilitar a participação dos pais, comunidades e organizações de pessoas com deficiência no planejamento e na tomada de decisões sobre os serviços na área das necessidades educativas especiais. (DECLARAÇÃO DE SALAMANCA, 1994).

Enquanto isso, no Brasil, a Legislação que defende a inclusão de crianças portadoras de deficiência em escolas regulares de ensino iniciou a fundamentação das leis com a Constituição de 1988, que prevê, em seu Artigo 208, que é dever do Estado fornecer "o atendimento educacional especializado aos portadores de deficiência, preferencialmente na rede regular de ensino" (MOREJÓN, 2007, p. 14).

Já no ano de 1989, dispondo da Lei ํㅜ‥853, também afirma os direitos das pessoas com deficiência, entre eles o referente à educação deliberando sobre as obrigações do Poder Público:

"Art. $2^{\circ}$ Ao poder público e seus órgãos cabe assegurar às pessoas portadoras de deficiência o pleno exercício de seus direitos básicos, inclusive dos direitos à educação, ao trabalho, ao lazer, à previdência social, ao amparo à infância e à maternidade, e de

\footnotetext{
${ }^{1}$ Mestranda em Ciências da Educação pela FICS-Facultad Interamericana de Ciências Sociales Licenciada em Ciências Biológicas. Especialista em Análise Clínicas e Patológicas. Especialista em Educação ambiental. Licenciada em Filosofia. Especialista em Educação Especial e Inclusiva. E-mail: polianaalmanca@hotmail.com.

${ }^{2}$ Mestranda em Ciências da Educação pela FICS-Facultad Interamericana de Ciências Sociales- Especialista em Educação Especial pela faculdade São Francisco- Graduada em Pedagogia pela Fundação Universidade Do Tocantins, E-mail: rosane_santos2@hotmail.com.
} 
outros, que decorrentes da Constituição e das leis, propiciem seu bem-estar pessoal, social e econômico". (POLIA, 2008, p. 71)

Além desses, em 1990 é reconhecido, através do Estatuto da Criança e do Adolescente, no seu Capítulo IV - Do Direito à Educação, à Cultura, ao Esporte e ao Lazer, Artigo 54, que "é dever do Estado assegurar à criança e ao adolescente: Inciso III - Atendimento educacional especializado aos portadores de deficiência, preferencialmente na rede regular de ensino" (MOREJÓN, 2007, p. 15). Sem contar com os documentos que são promulgados após a Declaração de Salamanca que também defendem a ideia de inclusão, como por exemplo, as Leis de Diretrizes e Bases da Educação Nacional (1996), Decreto no 3298 (1999), Lei 10.098 (2000), Plano Nacional de Educação - Lei 10.172 (2001), entre outros.

Em disposição de conceito, a inclusão social é caracterizada como um processo pelo qual a sociedade se adapta para poder incluir pessoas portadoras de necessidades especiais e, ao mesmo tempo, estas se preparam para assumir seus papéis na sociedade. Portanto, a inclusão se constitui em "um processo bilateral no qual as pessoas, ainda excluídas, e a sociedade buscam, em parceria, equacionar problemas, decidir sobre soluções e efetivar a equiparação de oportunidades para todos." (SASSAKI, 2003, p. 41).

Como pudemos verificar as legislações existentes, a inclusão de alunos portadores de deficiência está presente em Leis Internacionais e Nacionais, mas e na prática, será que a inclusão acontece? Se não, o que é preciso mudar para que essa inclusão ocorra?

Sassaki (2003) nos diz que "pelo modelo social da deficiência, os problemas da pessoa com necessidades especiais não estão nela tanto quanto estão na sociedade". A partir disso podemos perceber que a dificuldade maior ainda está na sociedade excludente. É preciso que a sociedade se modifique a partir do entendimento de que ela é que precisa ser capaz de atender às necessidades de seus membros. Esta é chamada a ver que ela cria as barreiras para os problemas das pessoas portadoras de necessidades especiais, causando sentimentos de incapacidade no desempenho dos papéis sociais desses indivíduos.

\footnotetext{
${ }^{1}$ Mestranda em Ciências da Educação pela FICS-Facultad Interamericana de Ciências Sociales Licenciada em Ciências Biológicas. Especialista em Análise Clínicas e Patológicas. Especialista em Educação ambiental. Licenciada em Filosofia. Especialista em Educação Especial e Inclusiva. E-mail: polianaalmanca@hotmail.com.

${ }^{2}$ Mestranda em Ciências da Educação pela FICS-Facultad Interamericana de Ciências Sociales- Especialista em Educação Especial pela faculdade São Francisco- Graduada em Pedagogia pela Fundação Universidade Do Tocantins, E-mail: rosane_santos2@hotmail.com.
} 
"Cabe, portanto, à sociedade eliminar todas as barreiras físicas, programáticas e atitudinais para que as pessoas com necessidades especiais possam ter acesso aos serviços, lugares, informações e bens necessários ao seu desenvolvimento pessoal, social, educacional e profissional." (SASSAKI, 2003, p. 47)

A inclusão social e a consequente inclusão escolar constituem uma nova perspectiva para a sociedade que desejamos construir. Há a necessidade de um novo paradigma que estabeleça programas políticos e sociais que a própria sociedade possa desenvolver e adaptar-se para respeitar e aceitar as diferenças de cada cidadão. Uma sociedade na qual todos se empenhem em buscar o bem-estar de toda a população, permitindo, inclusive, às pessoas portadoras de deficiência o acesso a todos os setores desta mesma sociedade, de forma igualitária (MOREJón, 2001, p. 37).

A construção de uma sociedade inclusiva é um processo de fundamental importância para o desenvolvimento e a manutenção de um Estado democrático. Por isso que se entende por inclusão a garantia, a todas as pessoas, do acesso contínuo a vida em sociedade, orientada por relações de acolhimento a diversidade humana e do esforço coletivo na equiparação de oportunidades (MACHADO; LABEGALINI, 2007, p. 62).

A inclusão:

“(...) questiona não somente as políticas e a organização da educação especial e regular, mas também o conceito de mainstreaming. A noção de inclusão institui a inserção de uma forma mais radical, completa e sistemática. O vocábulo integração é abandonado, uma vez que o objetivo é incluir um aluno ou um grupo de alunos que já foram anteriormente excluídos; a meta primordial da inclusão é a de não deixar ninguém no exterior do ensino regular, desde o começo. As escolas inclusivas propõem um modo de se constituir o sistema educacional que considera as necessidades de todos os alunos e que é estruturado em virtude dessas necessidades. A inclusão causa uma mudança de perspectiva educacional, pois não se limita a ajudar somente os alunos que apresentam dificuldades na escola, mas apoia a todos: professores, alunos, pessoal administrativo, para que obtenham sucesso na corrente educativa geral." (MANTOAN apud SASSAKI, 2003, p. 114)

\footnotetext{
${ }^{1}$ Mestranda em Ciências da Educação pela FICS-Facultad Interamericana de Ciências Sociales Licenciada em Ciências Biológicas. Especialista em Análise Clínicas e Patológicas. Especialista em Educação ambiental. Licenciada em Filosofia. Especialista em Educação Especial e Inclusiva. E-mail: polianaalmanca@hotmail.com.

${ }^{2}$ Mestranda em Ciências da Educação pela FICS-Facultad Interamericana de Ciências Sociales- Especialista em Educação Especial pela faculdade São Francisco- Graduada em Pedagogia pela Fundação Universidade Do Tocantins, E-mail: rosane_santos2@hotmail.com.
} 
Mendes (2002) coloca que se de fato há uma política de educação inclusiva em implantação, deveria ser possível observar ações em três componentes básicos de apoio: o aspecto político (administrativo e organizacional) que exige a construção de uma rede de suportes ou apoios capaz de atender às necessidades de formação pessoal, à provisão de serviços (centrados na escola, na comunidade ou na região) e ao planejamento e avaliação das diretrizes políticas almejadas; o aspecto educacional onde seria necessário planejar, implementar e avaliar programas para diferentes alunos em ambientes de escola regular; e o aspecto pedagógico que ressalta a importância das escolas implantarem classes inclusivas, o que pressupõe, entre outras coisas, a adoção intencional de agrupamentos heterogêneos, a centralização de apoios preferencialmente nas classes comuns, uso de estratégias de ensino que favoreçam a inclusão e o ensino multinível.

\section{EDUCAÇÃO INCLUSIVA}

Segundo a (Lei Diretrizes Curriculares Nacionais da Educação Básica), em janeiro de 2008, a nova "Política Nacional de Educação Especial na perspectiva da Educação Especial" da SEESP/MEC é publicada, passando a orientar os sistemas educacionais para organização dos serviços e recursos da Educação Especial de forma complementar ao ensino regular, como oferta obrigatória e de responsabilidade dos sistemas de ensino. Esta política resgata o sentido da Educação Especial expresso na constituição federal de 1988, que interpreta esta modalidade não substituta da escolarização comum e define a oferta do atendimento educacional especializado-AEE em todas as etapas, neveis e modalidades, preferencialmente no atendimento à rede pública.

Alguns autores tentam definir inclusão a partir da definição de exclusão. Segundo Sposati (1996), inclusão e exclusão são processos sociais interdependentes vinculados principalmente à distribuição de renda e oportunidades. Nesse sentido, Azevedo e Barros (2004) consideram a inclusão como o movimento permanente na busca de igualdade de condições e oportunidades para evitar diversas situações de privação. Esta definição pode ser considerada um tanto limitada, pois a inclusão não pode ser pensada em

\footnotetext{
${ }^{1}$ Mestranda em Ciências da Educação pela FICS-Facultad Interamericana de Ciências Sociales Licenciada em Ciências Biológicas. Especialista em Análise Clínicas e Patológicas. Especialista em Educação ambiental. Licenciada em Filosofia. Especialista em Educação Especial e Inclusiva. E-mail: polianaalmanca@hotmail.com.

${ }^{2}$ Mestranda em Ciências da Educação pela FICS-Facultad Interamericana de Ciências Sociales- Especialista em Educação Especial pela faculdade São Francisco- Graduada em Pedagogia pela Fundação Universidade Do Tocantins, E-mail: rosane_santos2@hotmail.com.
} 
apenas um dos aspectos sociais. Os autores citados definem inclusão a partir da exclusão, sendo a mesma.

No Brasil, a Constituição de 1988, assim como a LDB 9.394/96 (Lei de Diretrizes e Bases da Educação Nacional) destaca a importância e urgência de promover-se a inclusão educacional como elemento formador da nacionalidade. Os sistemas educacionais federais, estaduais e municipais, assim como a rede privada de escolas, têm envidado esforços no sentido de operacionalizar os dispositivos legais que exigem ou amparam iniciativas no caminho da inclusão escolar.

A inclusão educacional é, certamente, o caminho definitivo para que deixemos de ser o país de maior riqueza (potencial) e, ao mesmo tempo, palco das maiores injustiças sociais da história da humanidade. (Prof. Thiago Luiz M.de oliveira, Artigo, Inclusão escolar: um desafio constante, 27/07/1997)

O Instituo Nacional de Estudos e Pesquisas Educacionais Anísio Teixeira - INEP, em seu Informativo de $\mathrm{n}^{\circ} \mathbf{7 4}$ de 26 de jan. 2005, diz que o crescimento de matrículas em classes inclusivas supera o crescimento global. As matrículas de alunos com necessidades especiais em classes comuns (inclusivas) atingiram 34,6\% em 2004, enquanto as matrículas globais desse tipo de atendimento cresceram 12,4\%, segundo dados do Censo Escolar 2004.

\section{INCLUSÃO EDUCACIONAL}

No que se afirmar no LUFT (1998), nunca como hoje ouvimos dizer tanto a respeito de inclusão, especialmente nos mais diversos meios de comunicação.

De acordo com o dicionário LUFT (1998), inclusão é o ato ou efeito de incluir-se, ou seja, é fazer parte de algo, é ser inserido. São várias as formas de se abordar esta palavrinha já tão explorada pela mídia: inclusão digital, inclusão social e porque então não falarmos da inclusão educacional a pedra fundamental deste trabalho monográfico.

\footnotetext{
1 Mestranda em Ciências da Educação pela FICS-Facultad Interamericana de Ciências Sociales Licenciada em Ciências Biológicas. Especialista em Análise Clínicas e Patológicas. Especialista em Educação ambiental. Licenciada em Filosofia. Especialista em Educação Especial e Inclusiva. E-mail: polianaalmanca@hotmail.com.

${ }^{2}$ Mestranda em Ciências da Educação pela FICS-Facultad Interamericana de Ciências Sociales- Especialista em Educação Especial pela faculdade São Francisco- Graduada em Pedagogia pela Fundação Universidade Do Tocantins, E-mail: rosane_santos2@hotmail.com.
} 
FERREIRA e GUIMARÃES (2003), ao tratarem do tema educação inclusiva enfocam que comete engano à pessoa que pensa a respeito deste tema e faz ligação apenas às crianças com algum tipo de necessidade especial.

Consoante a este pensamento MITTLER, Peter (2003 p.25) diz que: "Isto se refere a todas as crianças que não estão beneficiando-se com a escolarização e não apenas aquelas que são rotuladas com o termo necessidades educacionais especiais".

Neste sentido afirma MITTLER, Peter (2003 p.25), deve-se entender que na sociedade contamos com as mais variadas diferenças: como cultural, financeira ou física, por exemplo, falar em inclusão principalmente educacional destes mais variados públicos é entender que não se trata de "mudar" o modo de ensinar apenas para atender os tidos como portadores de necessidades especiais, mas com o objetivo de atender a todos os alunos que possuem algum tipo de dificuldade de aprendizado, sempre com respeito e compreensão.

A educação inclusiva segundo RODRIGUES, Armindo J. Apud RIBEIRO e BAUMEL (2003), não deve ser tratada como uma abordagem tradicional onde era sinônimo de uniformização, mas numa abordagem de atenção a diversidade e a igualdade com respeito pelas diferenças e pelas necessidades individuais, desenvolvendo as potencialidades de cada aluno através de percursos individualizados de aprendizagem, respeitando as características e o ritmo de cada um. MITTLER, Peter (2003, p.20) afirma sobre inclusão no ato de educar que:

A inclusão depende do trabalho cotidiano dos professores na sala de aula e do seu sucesso em garantir que todas as crianças possam participar de cada aula e da vida da escola como um todo. Os professores, por sua vez, necessitam trabalhar em escolas que sejam planejadas e administradas de acordo com linhas inclusivas e que sejam apoiadas pelos governantes, pela comunidade local, pelas autoridades educacionais locais e acima de tudo pelos pais.

Observamos aqui de acordo com o autor MITTLER Peter (2003, p.20), que esta tarefa vai muito além da sala de aula e não depende tão somente do educador. $O$ aprendizado

\footnotetext{
${ }^{1}$ Mestranda em Ciências da Educação pela FICS-Facultad Interamericana de Ciências Sociales Licenciada em Ciências Biológicas. Especialista em Análise Clínicas e Patológicas. Especialista em Educação ambiental. Licenciada em Filosofia. Especialista em Educação Especial e Inclusiva. E-mail: polianaalmanca@hotmail.com.

${ }^{2}$ Mestranda em Ciências da Educação pela FICS-Facultad Interamericana de Ciências Sociales- Especialista em Educação Especial pela faculdade São Francisco- Graduada em Pedagogia pela Fundação Universidade Do Tocantins, E-mail: rosane_santos2@hotmail.com.
} 
inclusivo desta forma deve ser construído dia após dia com o auxílio e acompanhamento de todas as esferas sociais desde a família ao governo.

\section{O QUE ESPERAR DA EDUCAÇÃO INCLUSIVA}

Ao olharmos a prática educacional nas últimas décadas vem sofrendo modificações nos aspectos históricos, culturais e sociais. Neste sentido, PERRENOUD (1988) apud NÓVOA, Antônio (2007 p.14) diz que: Ao longo das últimas décadas, os especialistas da educação têm-se esforçado por racionalizar o ensino procurando controlar a priori os fatores aleatórios e imprevisíveis do ato educativo, expurgando o cotidiano pedagógico de todas as práticas, de todos os tempos que não contribuem para o trabalho escolar propriamente dito.

Essa "reforma" educacional a que se refere Perrenoud, a fim de tornar a educação mais objetiva no trabalho escolar deve-se segundo RODRIGUES, David (2006), ao desenvolvimento tenaz da exclusão, o que estimulou os responsáveis políticos a unir esforços em campanhas para sua eliminação, nos mais diversos domínios sociais.

Nesses domínios sociais citados por Rodrigues, inclui-se também a base da sociedade: A Educação. O que consoante a MITTLER, Peter (2003, p.15), sobre a reforma tratada por Perreunoud, não foi apenas por causa dos políticos, como afirma Rodrigues, tão pouco porque estes políticos aguardaram os pesquisadores dizerem a palavra certa, mas porque a sociedade exigiu tais mudanças. Todos os sistemas existentes, só são passíveis de mudanças, quando esta passa a incomodar o regime de imposição de seus governantes.

Segundo RODRIGUES (2006), essa exigência acabou causando nas últimas décadas várias mudanças no ensino, nos currículos escolares, nas leis de acessibilidade e principalmente a criação de um novo modelo educativo: A Educação Inclusiva. Este novo modo de educar vem propor novos questionamentos, talvez impensáveis até o momento, mais criativos e com melhores resultados como podemos ver nas escolas inclusivas. MITTLER, Peter (2003, p.16) a este respeito afirma que: A inclusão não diz respeito a

\footnotetext{
${ }^{1}$ Mestranda em Ciências da Educação pela FICS-Facultad Interamericana de Ciências Sociales Licenciada em Ciências Biológicas. Especialista em Análise Clínicas e Patológicas. Especialista em Educação ambiental. Licenciada em Filosofia. Especialista em Educação Especial e Inclusiva. E-mail: polianaalmanca@hotmail.com.

${ }^{2}$ Mestranda em Ciências da Educação pela FICS-Facultad Interamericana de Ciências Sociales- Especialista em Educação Especial pela faculdade São Francisco- Graduada em Pedagogia pela Fundação Universidade Do Tocantins, E-mail: rosane_santos2@hotmail.com.
} 
colocar as crianças nas escolas regulares, mas a mudar as escolas para torná-las mais responsivas às necessidades de todas as crianças, diz respeito a ajudar todos os professores a aceitarem a responsabilidade quanto à aprendizagem de todas as crianças que estão atual e correntemente excluídas das escolas por qualquer razão. Isto se refere a todas as crianças que não estão beneficiando-se com a escolarização, e não apenas aquelas que são rotuladas com o termo "necessidades educacionais especiais". Ainda neste autor, no que diz respeito à educação inclusiva, Mittler, após muitas pesquisas, observou que o maior obstáculo a ser superado no momento da mudança está dentro de nós, onde nossa tendência é subestimar as pessoas e superestimar as dificuldades, e que este pensamento deve ser abandonado ao se querer construir uma escola ou uma sociedade inclusiva, pois, segundo ele a inclusão se dá no ato de cada indivíduo ser capaz de ter oportunidades de escolher e de ter autodeterminação na educação e para que isto seja estimulado existe a necessidade de os educadores aprenderem a ouvir e valorizar o que o aluno tem a dizer, independentemente de sua idade ou de rótulos. Todo o conhecimento de mundo que o aluno traz consigo é importante, pois, deste remonta toda a sua história de vida que não pode e nem deve ser Espera-se que com a educação inclusiva sejam abandonadas definitivamente as barreiras celetistas de aprendizagem observado ao longo das décadas, onde poucos eram privilegiados com o acesso ao saber como afirma FREITAS, Soraia Napoleão Apud RODRIGUES (2006 p.162): ignorado pelo educador.

Ainda no que se afirmarem os autores FREITAS, Soraia Napoleão Apud RODRIGUES (2006 p.162): Percorrendo os diferentes períodos da história universal, desde os mais remotos tempos, evidenciam-se teorias e práticas segregadores, inclusive quanto ao acesso ao saber. Poucos podiam participar dos espaços sociais nos quais se produziam e transmitiam conhecimento.

Mas afinal por onde começar as mudanças para que estas práticas possam ser reformuladas a fim de atender as diversidades e as necessidades educacionais?

Neste assunto, RODRIGUES, Armindo de J. Apud RIBEIRO e BAUMEL (2003, p. 24) afirma que:

\footnotetext{
${ }^{1}$ Mestranda em Ciências da Educação pela FICS-Facultad Interamericana de Ciências Sociales Licenciada em Ciências Biológicas. Especialista em Análise Clínicas e Patológicas. Especialista em Educação ambiental. Licenciada em Filosofia. Especialista em Educação Especial e Inclusiva. E-mail: polianaalmanca@hotmail.com.

${ }^{2}$ Mestranda em Ciências da Educação pela FICS-Facultad Interamericana de Ciências Sociales- Especialista em Educação Especial pela faculdade São Francisco- Graduada em Pedagogia pela Fundação Universidade Do Tocantins, E-mail: rosane_santos2@hotmail.com.
} 
As mudanças deverão necessariamente começar nas concepções pedagógicas dos professores e em suas atitudes para com os alunos em dificuldade. A perspectiva pessoal do professor informará toda a sua construção e implementação de esquemas e rotinas.

O autor aqui propõe um novo olhar dos educadores, primeiramente nos seus próprios conceitos pedagógicos e logo após isso, para os alunos que tendem a aprender com menos facilidade, buscando desta forma uma readequação a fim de atendê-los de uma melhor forma.

Sabe-se que não podemos inovar todos os dias, mas se houver desejo, assessoria e disponibilidade, podemos testar muitas habilidades em salas de aulas, que virão a ajudar no desenvolvimento intelectual destes alunos.

Na perceptiva dos autores RODRIGUES, Armindo de J. Apud RIBEIRO e BAUMEL (2003, p. 24), a inclusão dos alunos com necessidades educativas especiais dependem não só da boa prática ou excelente formação do professor. Incluir com a finalidade educacional exige atitude e colaboração dos colegas em relação aos alunos integrados, a família, a comunidade, fatores socioeconômicos e socioculturais. Mas e a escola, qual o seu papel?

\section{ENSINO NAS ESCOLAS INCLUSIVAS: O OLHAR DESTE NOVO ENSINO E AS PRÁTICAS EDUCACIONAIS}

Segundo FERREIRA E GUIMARÃES (2003, p. 121), no mundo capitalista e de cultura individualista típico do mundo pós-industrial em que vivemos, onde o egoísmo e o preconceito fazem parte do cotidiano da sociedade e onde a tendência é o incentivo à competitividade, como numa selva que só sobrevive o "mais forte", ou neste caso o "o mais preparado", é papel fundamental da educação é fazer as pessoas refletirem sobre como superar os desafios impostos pela mesma sociedade que exige a "inclusão".

Desta maneira, a construção e a socialização do conhecimento pelos educadores devem contribuir para a autonomia dos seus alunos onde os mesmos possam construir seus

\footnotetext{
${ }^{1}$ Mestranda em Ciências da Educação pela FICS-Facultad Interamericana de Ciências Sociales Licenciada em Ciências Biológicas. Especialista em Análise Clínicas e Patológicas. Especialista em Educação ambiental. Licenciada em Filosofia. Especialista em Educação Especial e Inclusiva. E-mail: polianaalmanca@hotmail.com.

${ }^{2}$ Mestranda em Ciências da Educação pela FICS-Facultad Interamericana de Ciências Sociales- Especialista em Educação Especial pela faculdade São Francisco- Graduada em Pedagogia pela Fundação Universidade Do Tocantins, E-mail: rosane_santos2@hotmail.com.
} 
próprios objetivos. Para PERRENOUD, não há forças sociais importantes que exijam uma escola mais eficaz... Mesmo os que estão convencidos de que a escola tem de "se tornar mais eficaz" não estão prontos para elevar o nível de formação e de profissionalização dos professores. Eles têm novas expectativas relacionadas ao sistema educativo, porém não aceitam que ele seja um pouco mais oneroso.

Embora de acordo com o autor haja dificuldades e desestimulo dos educadores, por parte das pessoas que estão no topo do sistema educacional, que por coincidência são os mesmos que pressionam para uma reformulação.

\section{OS DOCENTES E O USO DAS TECNOLOGIAS ASSISTIVAS PARA A INCLUSÃO DE ALUNOS COM NECESSIDADES ESPECIAIS.}

No que se refere (ROCHA e CORTELAZZO, 2006, apud IOLANDA B. C. Cortelazzo et al, 2008). Sociedade em que vivemos deparamos constantemente com pessoas ao nosso redor vivenciando a exclusão social, esta é uma questão que tem sido tema de muitas pesquisas, fóruns e preocupações governamentais.

Felizmente, podemos contar com um forte aliado para a solução deste dilema social: A ciência e a tecnologia a qual estamos inseridos. É claro que construir uma sociedade inclusiva, significa muito mais que dominar tecnologias a favor da exclusão, significa também lidar com a diversidade humana e acreditar em princípios de justiça, igualdade e solidariedade, atitudes estas que podem ajudar a solucionar os problemas sociais que afetam o nosso país. (ROCHA e CORTELAZZO, 2006, apud IOLANDA B. C. Cortelazzo et al, 2008).

Sabemos que a geração de novos conhecimentos, a ciência e a tecnologia, por exemplo, devem estar a serviço de inovações tecnológicas e é neste contexto que encontramos a Tecnologia Assistiva, também denominada de adaptativa ou Ajuda Técnica. "todo e qualquer recurso que pode propiciar à pessoa que tem uma determinada deficiência autonomia suficiente para ser incluída". Socialmente, é tecnologia assistiva, seja esse

\footnotetext{
${ }^{1}$ Mestranda em Ciências da Educação pela FICS-Facultad Interamericana de Ciências Sociales Licenciada em Ciências Biológicas. Especialista em Análise Clínicas e Patológicas. Especialista em Educação ambiental. Licenciada em Filosofia. Especialista em Educação Especial e Inclusiva. E-mail: polianaalmanca@hotmail.com.

${ }^{2}$ Mestranda em Ciências da Educação pela FICS-Facultad Interamericana de Ciências Sociales- Especialista em Educação Especial pela faculdade São Francisco- Graduada em Pedagogia pela Fundação Universidade Do Tocantins, E-mail: rosane_santos2@hotmail.com.
} 
recurso um serviço, um procedimento, uma técnica, um equipamento (ROCHA e CORTELAZZO, 2006, apud IOLANDA B. C. Cortelazzo et al, 2008).

Ainda assim o autor acima se refere a tecnologia Assistiva então é aquela que vem a desenvolver ou permitir o aumento da autonomia e independência de pessoas, portadoras de deficiência ou qualquer outro tipo de necessidade, em suas atividades domésticas ou ocupacionais de vida diária.

Portanto, a aplicação de Tecnologia Assistiva abarca uma série de possibilidades do desempenho humano, desde tarefas básicas de autocuidado (mobilidade, comunicação, manutenção do lar, preparo de alimentos, tarefas ocupacionais), até atividades de lazer, de trabalho e aprendizado. (ROCHA e CORTELAZZO, 2006, apud IOLANDA B. C. Cortelazzo et al, 2008)

Tendo em consideração a obtenção de autonomia, ou a máxima autonomia possível, é com certeza, um dos caminhos para a perfeita inclusão social e constitui-se na premissa para qualquer intervenção em matéria de reabilitação e inclusão social. (ROCHA e CORTELAZZO, 2006, apud IOLANDA B. C. Cortelazzo et al, 2008)

\section{CONSIDERAÇÕES FINAIS}

É inegável a necessidade de se pensar uma verdadeira revolução em todo o contexto educacional. A inclusão dos alunos com necessidades especiais é tarefa primordial nessa nova empreitada, para tanto é necessário o implemento dos educadores com curso de aperfeiçoamento nesta área, mas principalmente para os que se encontram nas academias. Este trabalho tem como escopo, a inclusão educacional. Nesse âmbito, temos que contar com o contexto cultural, financeiro ou físico para atender a todos os alunos que possuem algum tipo de dificuldade de aprendizado. Esse é um processo que deve ser construído, dia após dia com a participação de todos os membros da sociedade.

É fácil se observar que a educação vem sofrendo modificações ao longo da sua história. Perrenoud (1988) ao propor uma reforma educacional pretende torná-la mais objetiva. A

\footnotetext{
${ }^{1}$ Mestranda em Ciências da Educação pela FICS-Facultad Interamericana de Ciências Sociales Licenciada em Ciências Biológicas. Especialista em Análise Clínicas e Patológicas. Especialista em Educação ambiental. Licenciada em Filosofia. Especialista em Educação Especial e Inclusiva. E-mail: polianaalmanca@hotmail.com.

${ }^{2}$ Mestranda em Ciências da Educação pela FICS-Facultad Interamericana de Ciências Sociales- Especialista em Educação Especial pela faculdade São Francisco- Graduada em Pedagogia pela Fundação Universidade Do Tocantins, E-mail: rosane_santos2@hotmail.com.
} 
partir dessa concepção, temos que: Todos os sistemas existentes, só são passíveis de mudança, quando esta passa a incomodar o regime de imposição de seus governantes. Essas mudanças no ensino, em busca de um novo modelo educativo, contemplam os anseios da Educação Inclusiva, que baseada em princípios e leis que reconhecem a necessidade de uma educação para todos, deixa bem claro que renovação pedagógica exige, em primeiro lugar, que a sociedade e a escola se adaptem ao aluno, e não o contrário. $\mathrm{E}$, em segundo, que o professor, considerado o agente determinante da transformação da escola, seja preparado adequadamente para gerenciar o acesso às informações e conhecimentos.

No mundo capitalista em que vivemos, onde o egoísmo e o preconceito fazem parte do cotidiano da sociedade é papel fundamental da educação fazer com que as pessoas passem a refletir, pois só assim será possível vencer os desafios impostos pela mesma sociedade que exige a "inclusão". O conhecimento é construído por aqueles que repassam o conteúdo, por isso carecemos de pessoas com habilidades para ensinar e aprender pelo processo da interação aluno x professor e a construção do saber. $A$ arte de ensinar, não pode partir do pressuposto de que existe aluno-padrão, pois a realidade que o educador enfrentará é bem diferente do que lhe é ensinado nas academias universitárias. Portanto, é preciso, antes de tudo estar preparado para as adversidades que a profissão impõe. A inclusão dos alunos com necessidades educativas especiais depende não só da boa prática ou excelente formação do professor. Neste assunto a escola também tem papel fundamental para a aprendizagem e facilitação da inclusão, como fornecer materiais didáticos adaptados, oferecer cursos aos educadores com a finalidade de conhecer novas práticas de ensino e adaptação no currículo escolar, por exemplo. Parece que no limiar de uma nova era, os indivíduos, organizações e entidades educacionais estão despertando para tornar, as pessoas com necessidades especiais, seres visíveis. Ao longo de nossa história é como se eles tivessem vivido a parte, em um universo onde somente o núcleo familiar fazia parte e, a formação do professor é a mola propulsora da sociedade educacional inclusiva. Precisamos mais que nunca, com atitudes melhoristas, minimizar essa mancha do preconceito que tanto já prejudicou e ainda insiste em existir em nosso convívio social.

\footnotetext{
${ }^{1}$ Mestranda em Ciências da Educação pela FICS-Facultad Interamericana de Ciências Sociales Licenciada em Ciências Biológicas. Especialista em Análise Clínicas e Patológicas. Especialista em Educação ambiental. Licenciada em Filosofia. Especialista em Educação Especial e Inclusiva. E-mail: polianaalmanca@hotmail.com.

${ }^{2}$ Mestranda em Ciências da Educação pela FICS-Facultad Interamericana de Ciências Sociales- Especialista em Educação Especial pela faculdade São Francisco- Graduada em Pedagogia pela Fundação Universidade Do Tocantins, E-mail: rosane_santos2@hotmail.com.
} 


\section{REFERÊNCIAS BIBLIOGRAFICAS}

ALENCAR, Eunice. M. L. Soriano. Artigo científico: $\mathbf{O}$ aluno com altas habilidades no contexto da educação inclusiva. Ano de publicação: 2006. Disponível em: http://scholar.google.com.br/scholar?q=O+ALUNO+COM+ALTAS+HABILIDADES+NO+ CONTEXTO+DA+EDUCA\%C3\%87\%C3\%830+INCLUSIVA\&hl=ptBR\&um=1\&ie=UTF-

$8 \& \mathrm{oi}=\mathrm{scholart}$

AZEVEDO, P.H e BARROS, J.F(2004), SPOSATI, A.A(1996), Artigo Inclusão social via acessibilidade digital: Proposta de inclusão digital para Pessoas com Necessidades Especiais1 Prof. Dra. Liliana Maria Passerino2 UFRGS liliana@cinted.ufrgs.br Prof. Dra. Sandra Portella Montardo3 FEEVALE sandramontardo@feevale.br, $\quad$ http://compos.org.br/seer/index.php/ecompos/article/view/144/145/acesso em 08/01/2018.

BASTOS, J. A. S. L. A. Educação e tecnologia: Educação \& Tecnologia: Revista Técnico-científica dos Programas de Pós- Graduação em Tecnologia dos CEFETs PR/MG/RJ - ano 1, abr. 1997. Curitiba: Centro Federal de Educação Tecnológica do Paraná, 1997.

BRASIL. Coordenadoria Nacional para Integração de Pessoas Portadoras de Deficiências. Declaração de Salamanca e Linhas de Ação sobre Necessidades Educacionais Especiais. Brasília: MEC, 1994.

BRASIL, Ministério da Educação. Diretrizes nacionais para a educação especial na educação básica. Secretaria de Educação Especial - MEC; SEESP, 2001.

BAYEN.M(2006), Artigo, Tópicos Especiais em Educação de Catiuscia Nagel, publi.20015, http://centraldeinteligenciaacademica.blogspot.com.br/2015/01/topicosespeciais-em-educacao-inclusiva.html/acesso em 08/01/2018.

CORTELAZZO, lolanda Bueno de Camargo; ROCHA, Carlos Alves; DI PALMA, Márcia Silva. Preparação dos docentes no uso das tecnologias assistivas para a inclusão

\footnotetext{
1 Mestranda em Ciências da Educação pela FICS-Facultad Interamericana de Ciências Sociales Licenciada em Ciências Biológicas. Especialista em Análise Clínicas e Patológicas. Especialista em Educação ambiental. Licenciada em Filosofia. Especialista em Educação Especial e Inclusiva. E-mail: polianaalmanca@hotmail.com.

${ }^{2}$ Mestranda em Ciências da Educação pela FICS-Facultad Interamericana de Ciências Sociales- Especialista em Educação Especial pela faculdade São Francisco- Graduada em Pedagogia pela Fundação Universidade Do Tocantins, E-mail: rosane_santos2@hotmail.com.
} 
de alunos com necessidades especiais. Curitiba: Universidade Tuiuti do Paraná, 2008.

ESTEVE, José M. Mudanças sociais e função docente. In: NÓVOA, Antonio (org.). Profissão professor. Porto: Porto, 1991. cap. 4, p. 94-124. 22

FERREIRA, Maria Elisa Caputo e GUIMARÃES, Marly. Educação inclusiva. Editora: DP \&A, 2008.

FREIRE, P. Pedagogia da autonomia. Rio de Janeiro: Paz e Terra, 1998

GINÉ, Climent, RUIZ, Robert. As adequações curriculares e o Projeto de

Educação do Centro Educacional. In: Coll, César et alli. Desenvolvimento psicológico e educação: necessidades educativas especiais e aprendizagem escolar. Porto Alegre: Artes Médicas, 1995.

HOLANDA, (1993),SALAMANQUE. Educação Inclusiva - um processo e um desafio. Em "Salamanque - Cinq ans après" - Rapport sur les activités de l'UNESCO à la lumière de la Déclaration de Salamanque et du Cadre d'Action - pp 9-10, Tradução Jorge Santos, 2008.

LEI DE DIRETRIZES CURRICULARES NACIONAIS DA EDUCAÇÃO BÁSICA. $(03 / 06 / 2009)$

SOUZA, Rita de Cácia e SILVA, Greice Santos. Desafios para o educador inclusivo.O educador frente à diversidade e à inclusão. Revista da FACED, № 09, 2005.

ZULIAN, Margaret Simone, FREITAS, Soraia Napoleão. Formação de professores na educação inclusiva: aprendendo a viver, criar, pensar e ensinar de outro modo. Revista do Centro de Educação, no 18. Ed. 2001.

http://br.monografias.com/trabalhos/educacao-inclusiva/educacao-inclusiva.shtml.

http://www.ambito-juridico.com.br/site/?n_link=revista_artigos_leitura\&artigo_id=8394

\footnotetext{
1 Mestranda em Ciências da Educação pela FICS-Facultad Interamericana de Ciências Sociales Licenciada em Ciências Biológicas. Especialista em Análise Clínicas e Patológicas. Especialista em Educação ambiental. Licenciada em Filosofia. Especialista em Educação Especial e Inclusiva. E-mail: polianaalmanca@hotmail.com.

${ }^{2}$ Mestranda em Ciências da Educação pela FICS-Facultad Interamericana de Ciências Sociales- Especialista em Educação Especial pela faculdade São Francisco- Graduada em Pedagogia pela Fundação Universidade Do Tocantins, E-mail: rosane_santos2@hotmail.com.
} 